Rajput, R. ${ }^{1}$, Jain, D. ${ }^{1}$, Kumar, A. ${ }^{1}$, Mittal, A. ${ }^{1}$

\title{
Typhoid Fever Presenting With Acute Renal Failure And Hepatitis Simultaneously - A Rare Presentation
}

${ }^{1}$ Department of Medicine, Pt. B.D. Sharma University of Health Sciences, ROHTAK-124001 (Haryana) INDIA

\begin{abstract}
Typhoid fever is an important health problem worldwide but its incidence is more in developing countries. Hepatic involvement is common, but both hepatic and renal involvement is rare in typhoid fever. We report a case of typhoid fever presenting with hepatitis and acute renal failure. A 17 year old male presenting with fever and pain abdomen was found to have raised blood urea, creatinine, liver enzymes and bilirubin. Widal and typhidot $(\operatorname{IgM}, \operatorname{IgG})$ test were positive. His symptoms subsided and deranged parameters resolved with treatment of typhoid fever.
\end{abstract}

Keywords: Typhoid fever, hepatitis, acute renal failure, Widal test.

Jain Deepak

Department of Medicine

Pt. B.D. Sharma University of Health Sciences,

Rohtak-124001 (Haryana), India

e-mail: jaindeepakdr@gmail.com

phone: +91-9416147887

\section{Introduction}

Typhoid Fever is a systemic prolonged febrile illness caused by Salmonella typhi with high risk of complications. It is major health problem especially in developing countries due to poor sanitation. Current estimates from the WHO suggest that the worldwide incidence of typhoid fever is approximately 16 million cases annually with $>600,000$ deaths [1]. The disease is endemic in India and carries a significant morbidity and mortality in both pediatric and adult populations. Reliable data to estimate the burden of disease in these areas is difficult to obtain. Typhoid fever may cause mild hepatic dysfunction and but acute hepatitis is uncommon. Renal complications are pyelonephritis and cystitis which may present with typhoid fever but acute renal failure is rare. Our case presented with severe impairment of both renal and hepatic functions. Acute hepatitis together with renal dysfunction is a rare presentation [2]. In best of our knowledge no such case has been reported from Indian subcontinent. 


\section{Case Report}

A 17 years old male presented with history of intermittent high grade fever not associated with chills and rigors and pain abdomen from last 15 days. Pain abdomen was diffuse, non-radiating and moderate to severe in intensity. He also complained of loose stools and vomiting from last 3 days. There was no history of cough, sore throat, burning micturition, hematuria, joint pains, drug intake and blood transfusion. On examination he was febrile $(38.7 \mathrm{oC})$, pulse rate $102 /$ minute, blood pressure $110 / 70 \mathrm{~mm}$ of $\mathrm{Hg}$. He was having pallor, icterus, bilateral pedal edema and normal jugular venous pressure. On palpation there was mild diffuse abdominal tenderness, mild splenomegaly ( 2 centimeter from left costal margin) hepatomegaly (4 centimeter from right costal margin) and no free fluid present in abdomen. Other systemic examination for respiratory, cardiovascular and central nervous system was essentially normal.

On admission his hemoglobin was $10.9 \mathrm{~g} / \mathrm{dl}$, total leukocyte count 4600 /cubic $\mathrm{mm}$ and erythrocyte sedimentation rate (ESR) $10 \mathrm{~mm} / 1 \mathrm{st}$ hour. Urine complete examination was normal and negative for cast, pus cell and red blood cells. Blood urea was $159 \mathrm{mg} / \mathrm{dl}$ and serum creatinine $3.1 \mathrm{mg} / \mathrm{dl}$. Liver function tests were also deranged with aspartate transaminase (AST) 203U/L, alanine transaminase (ALT) $196 \mathrm{U} / \mathrm{L}$ and serum total bilirubin $15.6 \mathrm{mg} / \mathrm{dl}$ (direct bilirubin $-11.5 \mathrm{mg} / \mathrm{dl}$ ). Widal test showed raised titres of antigens $\mathrm{T}(\mathrm{O})$ and $\mathrm{T}(\mathrm{H}) 1: 250$ both on 1st day and rose to 1:640 on 4th day. Blood culture showed growth of Salmonella typhi and typhidot (IgM, IgG) was also positive. Serology for anti HAV, HBsAg, anti HCV and HIV was negative. Peripheral blood smear and malaria antigen card test were negative for malaria, Dengue card test, serological tests (IgG and IgM) for scrub typhus and leptospiral were negative. Antinuclear antibody was negative, ASO titre and complement $(\mathrm{C} 3, \mathrm{C} 4)$ level were within normal limits. ECG and chest $\mathrm{x}$ ray were normal. Ultrasound showed mild hepatosplenomegaly and kidneys with normal size and echotexture.

He was started on intravenous ceftriaxone
$2 \mathrm{gm}$ daily and symptomatic treatment. He responded well to therapy and his parameters started to improve and he was discharged after ten days of treatment. On discharge his blood urea was $27 \mathrm{mg} / \mathrm{dl}$, serum creatinine $0.8 \mathrm{mg} / \mathrm{dl}$, AST/ALT - $37 / 71 \mathrm{U} / \mathrm{L}$ and serum bilirubin $2.4 \mathrm{mg} / \mathrm{dl}$. His all investigations were within normal limits on follow up in outpatient department after two weeks.

\section{Discussions}

Typhoid fever is more prevalent in developing countries and considered as endemic disease in Indian subcontinent. Its major morbidity and mortality is due to its complications. Typhoid fever may affect any organ of body in form of pneumonitis, hepatitis, intestinal perforation etc.

Hepatomegaly and moderate elevation of transaminase levels are the common findings that occur in $21-60 \%$ of cases of typhoid fever [3]. However, severe hepatic derangement simulating acute viral hepatitis is very rare. The documented incidence varies widely from less than $1 \%$ to $26 \%$ patients with enteric fever. The clinical course can be severe with a mortality rate as high as $20 \%$, particularly with delayed treatment or in patients with other complications of Salmonella infection [4]. A positive culture for salmonella from blood or stool is essential to differentiate salmonella hepatitis from other causes of acute hepatitis. The mechanism of hepatic damage is obscure. Biochemical evidence of liver dysfunction may result from invasion of the liver by Salmonella or from a high concentration of endotoxins which damage the hepatocytes [5]. The bacteria may also proliferate in the hepatocytes and produce hepatic damage by stimulating the synthesis and release of cytokines[6]. Recognition of this clinical condition is particularly important in tropical countries where malaria and viral hepatitis are quite common.

Renal involvement in typhoid is called 'nephrotyphoid' and can be due to immune 
complex mediated glomerular damage and presents as hematuria, albuminuria, azotemia, nephritis, pyelonephritis or glomerulonephritis [7]. Other types of renal involvement in typhoid fever are: Ig A nephropathy and post vaccination nephropathy following typhoid vaccination. Typhoid nephritis in adults, as a complication of untreated typhoid carries a very high mortality of $20-30 \%$ [8,9]. Acute renal failure is very uncommon in typhoid patient. It may be a part of septicemia or shock. Very rarely acute renal failure in typhoid fever may occur due intravascular hemolysis caused by typhoid fever [10]. Acute renal failure and hepatitis occurring simultaneously in a patient with typhoid fever is very rare. Early recognition and prompt treatment is instrumental in reducing morbidity and mortality.

\section{Conclusions}

Patients having fever with deranged hepatorenal functions are usually evaluated for malaria, leptospirosis and scrub typhus by clinicians, but typhoid fever is not considered as differential diagnosis. Our patient illustrates good example of how these reversible complications could occur associated with typhoid fever. It is to develop awareness for any clinician when they encounter such case, after ruling out the above causes, typhoid fever should also be suspected and timely intervention can prevent further morbidity and mortality in such cases.

\section{Acknowledgments}

All authors declare no conflict of interest and no external source of funding. All authors have read and approved the final manuscript.

\section{References}

1. Pang, T., Bhutta, Z.A., Finlay, B.B. \& Altwegg, M. (1995). Typhoid fever and other salmonellosis: a continuing challenge. Trends Microbiol. 3(7), 253-255.

2. Khan, M., Coovadia, Y.\& Sturm,A.W.(1998). Typhoid fever complicated by acute renal failure and hepatitis: case reports and review. Am J Gastroenterol. 93(6), 1001-1003. doi: 10.1111/j.1572-0241.1998.298_y.x

3. Khosla, S.N., Singh, R., Singh, G.P. \& Trehan, V.K. (1988). The spectrum of hepatic injury in enteric fever. Am J Gastroenterol. 83(4), 413-416.

4. Pramoolsinsap, C. \& Viranuvatti, V. (1998). Salmonella hepatitis. $J$ Gastroenterol Hepatol. 13(7), 745-750.

5. Khosla, S.N. (1990). Typhoid hepatitis. Postgrad Med J. 66)781), 923-925.

6. Morgenstern, R. \& Hayes, P.C. (1991). The liver in typhoid fever: always affected, not just a complication. Am $J$ Gastroenterol. 86(9), 1235-1239.

7. Williams, D.C. \& Adu, D. (1996). Infection associated nephropathy. In D.J. Weatherall, J.G.G. Ledingham \& D.A. Warrel (Eds), Oxford text book of Medicine (pp 31733179). Oxford University Press.

8. Chowdhury, K.L., Saproo, R.K., Bhat, M.Y., Ogra, R.K., Thussu, A., Jalali, R.K., Abrol, A., Pandita, P. \& Fotedar, A. (1988). Typhoid nephritis. J Assoc Physicians India. 36(7), 447448.

9. Buka, I. \& Coovadia, H.M. (1980). Typhoid glomerulonephritis. Arch Dis Child. 55(4), 305-307.

10. Ozen, H., Secmeer, G., Kanra, G., Ecevit, Z., Ceyhan, M., Dursun, A. \& Anlar, Y. (1995). Typhoid fever with very high transaminase levels. Turk J Pediatr. 37(2), 169-171. 